\title{
LA LUX INTELLIGENTIAE AGENTIS EN EL PENSAMIENTO DE DOMINGO GUNDISALVO
}

\author{
$M^{\mathfrak{a}}$ Jesús Soto Bruna \\ Universidad de Navarra
}

\section{RESUMEN}

El artículo presenta la teoría del conocimiento en el pensamiento de Domingo Gundisalvo y la culminación del proceso cognoscitivo en la luz «de la inteligencia agente» (intelligentiae agentis); luz de la cual participa el ser humano cuando se encuentra in effectu $o$ in adeptus ab alio. Expone esta concepción en consonancia con las tesis metafísicas que el Gundisalino sostiene en el De processione mundi.

Palabras clave: Luz, processio, inteligencia agente (intelligentia agens), intellectus in adeptus ab alio.

\begin{abstract}
This paper presents Domingo Gundisalvo's theory of knowledge and the end of our cognitive process at the light «of the active Intelligence» (intelligentiae agentis). For human beings participate in this light wen at in effectu or in adeptus ab alio. The research takes into account Gundisalvo's metaphysics background as exposed in his De processione mundi.
\end{abstract}

Key words: Light, processio, intelligentia agens, intellectus in adeptus ab alio.

\section{LA OBRA METAFÍSICA DE GUNDISALVO Y SU PERSPECTIVA GNOSEOLÓGICA}

La reflexión sobre la actividad intelectual del ser humano se halla en Domingo Gundisalvo expresamente vinculada a sus especulaciones sobre la estructura del universo creado y su dependencia de un Dios creador; de tal modo que la plena afirmación de la inteligibilidad que le corresponde al mundo, conlleva de modo paralelo la declaración o confirmación de que las potencias cognoscitivas humanas se hallan abocadas de un modo natural al conocimiento de la verdad de este cosmos, el cual refleja a su Hacedor. Consciente entonces de que la posibilidad del pensamiento metafísico no puede dejar fuera las dimensiones gnoseológicas fundamentales, se aplica al estudio del alma humana y la existencia en ella de una facultad que sea la encargada de dirigirse al conocimiento de lo que ya desde Aristóteles se ha denominado como «las cosas divinas» ${ }^{1}$. En este tema, los principios filosóficos gundisalinos suponen sin lugar a dudas un importante avance con respecto a los estudios médievales realizados hasta el primer cuarto del siglo XII. 
En efecto, el arcediano español del siglo XII Domingo Gundisalvo ocupa un lugar central en la configuración y sistematización del cuerpo de la filosofía medieval. Esto es debido, por un lado, al trabajo ejercido en uno de los centros culturales más renombrados e influyentes en la Europa de ese momento, en lo que se refiere a la recepción y transmisión de los nuevos documentos del pensamiento árabe al Occidente latino: la así denominada «Escuela de Traductores de Toledo», lugar de encuentro de las tres principales culturas del momento ${ }^{2}$; donde, entre otros, tradujo al latín la Metafísica de Avicena ${ }^{3}$; traducción que, de hecho, ayudó a Domingo Gundisalvo a presentar la teoría del conocimiento aviceniana a través de sus propios tratados - como veremos - sobre el alma y a presentar asimismo un nuevo análisis del intelecto agente. Es sabido además que colaboró, entre otros, en la traducción del Fons Vitae de Avicebrón ${ }^{4}$ : obras y autores que se encuentran presentes en su psicología filosófica.

Mas, por otro lado, el progresivo conocimiento y estudio de las obras traducidas, impulsó a nuestro autor a escribir algunos tratados independientes que incorporaban gran parte del legado transmitido, repensándolo a la luz de la filosofía latina desarrollada hasta entonces. De ahí que el estudio de su obra constituya una clave para la comprensión del desarrollo ulterior de determinados conceptos, entre los que se encuentra el que ha de ocupar aquí de un modo especial nuestra atención: el «intelecto agente», o, como se expresa frecuentemente en su tratado sobre el alma, «inteligencia agente». Gundisalvo constituye entonces un nuevo hito en la historia de las interpretaciones del De Anima de Aristóteles (III, 5, 430 a 10-19).

En este orden de cosas, se han atribuido a Dominicus Gundisalvi o Gundissalinus ${ }^{5}$ verdaderos tratados filosóficos; en los cuales se hallan incoadas algunas de la tesis metafísicas que van a ocupar la atención en un ámbito nuclear de la filosofía del siglo XIII. Así, aunque no es un pensador independiente - en el sentido moderno de esta última expresión- sus obras, en gran parte compilaciones de textos e ideas recogidos de otros autores, incluyen ciertas modi-

2 Cfr. García-Junceda, J. A., «La filosofía hispano-árabe y los manuscritos de Toledo. Una meditación sobre el origen de la escuela de traductores», en Anales del Seminario de Historia de la Filosofía, III (1982-83), pp. 6593; González Palencia, M., El arzobispo don Raimundo de Toledo, Barcelona, Labor, 1942; Menéndez Pidal, M., «España y la introducción de la ciencia árabe en Occidente», en Revista del Instituto Egipcio de Estudios islamicos en Madrid, III (1995), incluido en España, eslabón entre la Cristiandad y el Islam, Madrid, Espasa-Calpe, Austral, pp. 33-60; Millás Villacrosa, T., Las traducciones orientales en los manuscritos de la Biblioteca Catedral de Toledo, Madrid, C.S.I.C., 1942.

3 Cfr. París, B. N., lat. 6443, f 43: «Completus est liber quem transtulit Dominicus Gundisalvi archidiaconus Toleti de arabico in latinum». Cfr. D'Alverny, M.Th., «Notes sur les traductions médiévales des oeuvres philosophiques d'Avicenne», en Archives d'Histoire Doctrinale et Littéraire du Moyen Âge, 19 (1952), pp. 337-358.

4 Cfr. Avencebrolis (Ibn Gabirol) Fons Vitae ex arabico in latinum translatus ab Iohanne Hispano et Dominico Gundissalino. Ex codicibus parisinis, amploniano, columbino, ed. por: Cl. Baeumker, en Beiträge zur Geschichte der Philosophie des Mittelalters, Band I, Heft 3, Münster, 1892. Para una mayor información: Alonso, M., «Traducciones del arcediano Domingo Gundisalvo», en Al-Andalus, 12 (1947), pp. 295-338.

5 La identidad del personaje, dentro de las diversas acepciones latinas del nombre del autor puede hoy ser afirmada, dentro de una razonada investigación histórico-filosófica. Puede verse al respecto: Die dem Boethius falschlich zugeschriebene Abhandlung des Dominicus Gundisalvi De unitate, en Beiträge zur Geschichte der Philosophie des Mittelalters, Band I, Heft 1, Münster, 1891, p. 31: «Dominicus Gundisalvi ist der Verfasser der Abhandlung De unitate (Dominicus Gundisalvi, Gundissalinus, Gondisalinus, Gumdissalino). Más recientemente, la identidad y el nombre del autor que nos ocupa ha sido investigada y afirmada por: García Fayós, J., «El colegio de traductores de Toledo y Domingo Gundisalvo», en Revista de la Biblioteca, Archivo y Museo, 33 (enero 1932), pp. 109-123; Alonso Alonso, M., Temas filosóficos medievales (Ibn Dawud y Juan Hispano), Publicaciones de la Universidad Pontificia de Comillas, 1959, p. 22; Ribera, F., «Nuevos datos sobre los traductores Gundisalvo y Juan Hispano», Al-Andalus, 31 (1966), pp. 267-280; Díaz, G., Hombres y documentos de la filosofía española, Madrid, C.S.I.C, 1980. En 1999 la historiadora A. Rucquoi abogó por una división entre el traductor y el filósofo en su artículo: «Gundisalvus ou Dominicus Gundisalvi?», en Bulletin de philosophie médiévale, 41 (1999), pp. 85-106; a este artículo se hicieron algunas precisiones, abogando de nuevo por la unidad de autor y traductor: Fidora, A./ Soto Bruna, M.J., «Gundisalvus ou Dominicus Gundisalvi?». Algunas observaciones sobre un reciente artículo de Adeline Rucquoi», en Estudios Eclesiásticos, 76 (2001), pp. 467-473. 
ficaciones de lo recibido y proponen a la historia del pensamiento nuevas expresiones y planteamientos filosóficos que acogen gran parte del legado árabe, judío y también latino ${ }^{6}$.

La propuesta especulativa de Gundisalvo a partir de tales antecedentes puede situarse dentro de una corriente neoplatónica, que se aplica a la a la investigación metafísica de la estructura del mundo, con objeto de probar la existencia de una primera causa, que no será sino Dios como ser necesario y creador ex nihilo. Este razonamiento se encuentra explicitado en el De processione mundi ${ }^{7}$, obra en la que expone las coordenadas nucleares de su metafísica, acorde con la estructura del conocimiento y de las funciones de las facultades del alma que presenta en el De anima y en el De immortalitate animae ${ }^{8}$; habiéndose escrito de este último que «fue la primera presentación occidental de la metafísica aviceniana del alma, con los análisis que derivan de ahí relativos a la teoría del conocimiento (intelecto agente, intellectus adeptus)»9 . Es muy probable que esta obra sea posterior a la que hemos mencionado como metafísica, según al menos la opinión de G. Bülow en los Beiträge; aceptado lo cual, puede con certeza aseverarse que en el desarrollo de su pensamiento, el arcediano procede según el esquema clásico de la filosofía: de la estructura de los seres creados se dirige al modo conocimiento de los mismos, para culminar en su causa primera. Y es que, para él y en última instancia, la filosofía no es sino la assimilatio hominis operibus creatoris secundum virtutis humanitatis, un allegarse del hombre a las obras del creador según la fuerzas de la humana naturaleza (ed. de L. Baur, p. 6, 1-2).

Desde esa perspectiva, a Gundisalvo le interesa tanto el estudio de las «obras del creador» como la fundamentación de las «fuerzas de la humana naturaleza», de un modo tal que quede asegurada la posibilidad mencionada; esto es que el conocimiento humano pueda allegarse, en una cierta forma de asimilación, al conocimiento de las formas de las cosas y de su primera causa, que es principium agens et creans ${ }^{10}$. Es en este punto donde ha de jugar su papel la luz de la inteligencia agente.

6 Tal vez el caso más paradigmático de esta recepción se encuentre en el De divisione philosophiae, ed. de Baur, L., en Beiträge sur Geschichte der Philosophie des Mittelalters, Band IV, Heft 2-3, Münster, 1903; tratado que ha sido estudiado, entre otros por: Kinoshita, N., El pensamiento filosófico de Domingo Gundisalvo, Prólogo de Cruz Hernández, M., Universidad Pontificia de Salamanca, 1988, pp. 47-56; Fidora, A., «Die Rezeption der boethianischen Wissenschaftseinteilung bei Dominicus Gundissalinus» en Berndt, R., Lutz-Bachmann, Stammberger, Ralf M. W. (eds.), Scientia und Disciplina. Wissenstheorie und Wissenschaftspraxis im Wandel vom 12. zum 13. Jahrhundert, Belín, Akademie-Verlag, 2002, pp. 178-191. O también: De Scientiis / Domingo Gundisalvo; compilación a base principalmente de la «Magala fi ihsa» al-Bulum de Al-Farabí. Texto latino establecido por Alonso Alonso, M., Madrid, C.S.I.C. (Instituto Miguel Asín), 1954.

7 Des Dominicus Gundissalinus Schrift 'Von dem Hervorgange der Welt' (De processione mundi), ed. de Bülow, G., Beiträge zur Geschichte der Philosophie des Mittelalters, Band XXIV, Heft 3, Münster 1925; editada también por Menéndez Pelayo, M., Historia de los heterodoxos españoles, Madrid, Espasa-Calpe, Austral, 1992 (reed. De 1880), vol. II, pp. 189-221. Una nueva edición crítica, acompañada de la primera traducción al castellano de esta obra del Gundisalino se encuentra en: Soto Bruna, M.J./ Alonso del Real, C., De processione mundi. Estudio y edición crítica del tratado de D. Gundisalvo, Pamplona, Eunsa, Serie de Pensamiento Medieval y Renacentista, 1999: en las primeras 107 páginas de este libro he llevado a cabo una exposición de las líneas principales del pensamiento gundisalino; pudiéndose encontrar ahí la bibliografía más relevante al respecto. El De processione mundi será citado en este artículo según la última edición mencionada en esta nota.

8 De estas obras, de las que presumimos la auténtica autoría gundisalina en este artículo, se citarán aquí las siguientes ediciones: Muckle, J. T., Liber Dominici Gundisalini De Anima ex dictis plurium philosophorum collectus, en «De Anima of Dominicus Gundissalinus. Edited by J. T. Muckle, C. S. B., with an introduction by Etienne Gilson», en Medieaeval Studies, 2 (1940), pp. 23-103. Bülow, G., Des Dominicus Gundissalinus Schrift Von der Unsterblichkeit der Seele (Gundissalinus De immortalitate animae), herausgegeben und philosophiegeschichtlich untersucht, nebst einem Anhange, enthailtend die Abhandlung des Wilhelm von París (Auvergne) De immortalitate animae, en Beiträge zur Geschichte der Philosophie des Mittelalters, Band II, Heft 3, Münster 1897.

9 Chenu, M.D., La théologie au douzième siècle, parís, Vrin, 1966, p. 138.

10 De Anima, p. 93, 6. 


\section{INTELLECTUS E INTELLIGENTIA EN DE PROCESSIONE MUNDI}

En el De processione mundi explica la relación entre el creador y las criaturas, donde la processio se refiere al momento de la creación como difusión divina, en una interpretación ya cristiana del emanacionismo de corte platónico ${ }^{11}$; implicando la idea de que el mundo creado es una teofanía o manifestación de su primer principio. Processio muestra así la relación entre el primer ser, que es aquí unidad de simplicidad, y las realidades que de él proceden; siendo esencial a toda procesión el que se realice mediante semejanza de lo derivado con aquello de lo cual deriva. Con esta idea comienza precisamente la obra: «Las cosas invisibles de Dios son contempladas, inteligidas, por la criatura del mundo a través de las cosas que han sido creadas. Pues si contemplamos atentamente estas cosas visibles, precisamente a través de ellas subimos a la contemplación de las cosas invisibles de Dios. Pues las huellas del creador son las admirables obras de la criatura visible, y por eso rastreando a través de ellas, que de Él proceden, llegamos a Él mismo» ${ }^{12}$.

Desde estas premisas, el examen del proceso cognoscitivo reviste una importancia capital; pues - como acaba de leerse- únicamente la captación inteligible del ente creado permite el acceso a aquello - el Absoluto- que constituye el fin último del entendimiento y del filosofar racional. En este punto es aceptado en gran parte el esquema gabiroliano: el mundo de las criaturas aparece como una suerte de jerarquía de unidades, jerarquía que se establece según la proximidad o lejanía respecto de la primera unidad. En el nivel ínfimo se halla lo que es uno solamente por continuidad o agregación: la materia con cantidad; situándose en el nivel superior la unidad de la inteligencia, que es unidad de simplicidad y, por debajo de ésta, la unidad del alma, que es inferior por darse en ella la mutación y la diversidad.

De un modo paralelo a esa estructura ontológica, Gundisalvo establece el proceso cognoscitivo humano como una progresiva elevación, desde el conocimiento sensible hasta el conocimiento intelectual en su más alto grado, y apto para comprender la primera causa como forma simple. En este contexto, establece la importancia que ocupa la persona humana en el conjunto de la creación, en cuanto ser destinado a revelar «la potencia, sabiduría y bondad del creador, que son cosas invisibles de Dios» ${ }^{13}$. Para ello, el hombre consta de varias potencias cognoscitivas ordenadas escalonadamente: los sentidos aprehenden las cosas sensibles unidas en la materia; la imaginación las formas sensibles en la materia ausente; la razón aprehende las formas sin materia; el entendimiento o intelecto se dirige solamente a las formas inteligibles; $y$, por fin, la inteligencia capta una forma simple por completo, que no es sino la causa del universo: «Se asciende a la inteligencia por intelección o por demostración, al intelecto por la razón, a la razón a través de la imaginación, y a la imaginación por los sentidos. Pues los sentidos aprehenden las formas sensibles en una materia inmediatamente presente, la imaginación las formas sensibles en una materia ausente en ese momento, y la razón las formas sensibles aparte de la materia; el intelecto, sólo las formas inteligibles, y la inteligencia una sola forma simple. Por consiguiente, la mente humana contemplando asciende a Dios por estos escalones

11 El término es empleado en general en el neoplatonismo cristiano; se encuentra así en autores como: Pseudo-Dionisio Areopagita, Thierry de Chartres, Juan Eckhart, Juan Escoto Eriúgena o Nicolás de Cusa; cfr. a este respecto: Riccati, C., «Processio» et «explicatio». La doctrine de la création cez Jean Scot et Nicolas de Cues, Nápoles, Bibliópolis, 1983; Haring, M. H., «Thierry of Chartres and Dominicus Gundissalinus», en Medieaeval Studies, 26 (1964), pp. 271-286. También W. Beierwaltes afirma con nitidez la filiación neoplatónica de Gundisalvo en el tema que se refiere a la relación Dios-criaturas (o Unidad-multiplicidad), en Identität und Differenz, Frankfurt am Main, Klostermann, 1980, p. 50.

12 De processione mundi, ed. cit., n. 1. A partir de aquí, en esta obra va explicando Gundisalvo las tesis que sostuvo en el De unitate et. uno; cfr. Pastor García, J. T., «Domingo Gundisalvo, el arcediano segoviano», en Fartos Martínez, M. / Velázquez Campo, L. (coords.), La filosofía española en Castilla y León. De los orígenes al Siglo de Oro, Universidad de Valladolid, Secretariado de Publicaciones e intercambio científico, 1997, p. 67.

13 De processione mundi, n. 1. 
y la bondad divina desciende al hombre. La razón inquiere componiendo y resolviendo; resolviendo asciende, componiendo desciende. Pues en la resolución comienza desde las cosas últimas, y en la composición desde las primeras. Por tanto, a través de las cosas que han sido creadas, la criatura del mundo contempla, inteligidas, las cosas invisibles de Dios» ${ }^{14}$.

Del modo expuesto, la Unidad primera, que no es sino Dios en este sistema, constituye la cima trascendente de la que procede el universo entero; $y$, a su vez, es alcanzada - supuesto un riguroso paralelismo entre la ontología y la gnoseología- por la que asimismo constituye la cumbre de las facultades humanas: la inteligencia. Es digno de señalar que esta operación, mediante la cual la filosofía encuentra una estricta relación entre la estructura del universo y el proceso cognoscitivo se debe al replanteamiento gundisalino de las tesis avicenianas; de tal modo que puede sostenerse que el punto crítico en el que se efectúa la disociación entre la filosofía del s. XII y la del s. XIII es, precisamente, la teoría del conocimiento. Donde Gundisalvo ha jugado el papel principal, tratando precisamente de solucionar, desde un planteamiento ya cristiano, el problema del intelecto agente que había quedado sin resolver en Avicena ${ }^{15}$.

E. Gilson señaló en su momento que la distinción gundisalina entre el intelecto y la inteligencia correspondería a la distinción agustiniana entre la ratio inferior y la ratio superior; son sus palabras: «La ciencia es la comprehensión de la forma de una cosa por el intelecto o por la imaginación. Cuando la forma es captada por la imaginación, la ciencia es sensible. Cuando es captada por el intelecto, es inteligible. Para que haya ciencia inteligible es necesario que la forma se una al intelecto que la capta. Pero el alma no puede captar lo sensible sin intermediario, porque su modo de ser no es el mismo. Por el contrario, puede captar lo inteligible sin intermediario, pues su modo de ser es de la misma naturaleza. Cuando aprehende la verdad que se refiere a las cosas sensibles, pone en acción su intelecto y adquiere la ciencia; cuando aprehende la verdad que se refiere a los inteligibles, pone en obra su inteligencia y adquiere la sabiduria» ${ }^{16}$. Resultando así que el intelecto y la ciencia son útiles en la medida en la medida en que se dirigen a la inteligencia y a la sabiduría, que tiene por objeto la contemplación de las cosas invisibles de Dios; como resume Gundisalvo en el mismo De processione mundi: «Para la especulación hay tres cosas necesarias: razón, demostración e inteligencia. La razón es necesaria para la composición, la demostración para la disposición, para la causa la inteligencia» $^{17}$.

Ciertamente, resulta clara la influencia del agustinismo en Domingo Gundisalvo; aunque pueda ponerse hoy en cuestión la tesis de E. Gilson, según la cual Gundissalinus sería el iniciador de una corriente que él denomina como el «agustinismo avicenizante» ${ }^{18}$. En todo caso, ha de aceptarse que la explicación gilsoniana acerca de que el alma puede captar lo inteligible sin intermediario se refiere, a mi juicio, a la doctrina propia del Gundisalino de que con la adquisición de la sabiduría, la inteligencia se aquieta en la contemplación del ser supremo; y, además, que la virtud más noble del alma no tiene un instrumento correspondiente en el cuerpo: asunto éste clave para comprender las pruebas acerca de la inmortalidad del alma basadas en la actividad intelectiva y expuestas en el De immortalitate animae: «Essentia igitur intellectus

14 De processione mundi, n. 2. Cfr. Gilson, E., «Avicenne en Occident et au Moyen Âge», en Archives d'Histoire Doctrinale et Littéraire du Moyen Âge, 44 (1969), pp. 89-121.

15 Opinión sostenida por: Chenu, M.D., o.c., p. 103.

16 Gilson, E., «Pourquoi Saint Thomas a critiqué Saint Augustin», en Archives d'Histoire Doctrinale et Littéraire du Moyen Âge (1926-27), pp. 3-27; según este artículo, Santo Tomás no ha podido leer a Avicena más que mediante la traducción de Gundisalvo: p. 35, nota 2.

17 De processione mundi, n. 2.

18 Sobre el cuestionamiento de la tesis de E. Gilson: Fidora, A., «On the supposed 'Augustinisme Avicennisant' of Dominicus Gundissalinus», en Veritas (Porto Alegre), 47, n. 3 (sept. 2002), pp. 387-394; y, anteriormente, Teicher, J., «Gundissalino e l’Agostinismo Avicennizzante», en Rivista di Filosofia Neoscolastica (Milán), 26 (1934), pp. 252-257. 
non pendet ex corpore, cum eius operatio propria impediatur ab illo et per illus» ${ }^{19}$; por donde ya al nivel del intelecto se encuentra la separación de la materia que es requerida también para la actividad de la inteligencia, encargada, en esta vida, de acceder a la contemplación de la causa primera, por la cual se aquieta el proceso cognoscitivo; doctrina toda ella establecida asimismo en el De Anima: «Sed quia horum omnium sapientia cognitio est, ideo sapientia est comprehensio veritatis earum rerum quae sunt vere et quae sui immutabilem sortiuntur substantiam. Sicut autem per intellectum scientia sic sapientia per intelligentiam acquiritur, quae secundum Boethium paucorum admodum hominum est et solius Dei. Intelligentia enim est altior oculus animae quo se vel Deum et aeterna contemplando speculatur ${ }^{20}$. La inteligencia es, en el De processione mundi y en el De Anima, como el ojo más profundo del alma, con el que al mirar se ve a Dios y las cosas eternas. Para que esto tenga lugar, será preciso desarrollar una teoría de la luz, mediante la cual pueda explicarse la, por así decir, luminosidad de las cosas materiales que se hace patente a la luz intelectual.

\section{LA CONTEMPLACIÓN DE LA FORMA MEDIANTE LUCE INTELLIGENTIAE AGENTIS}

Gundisalvo alude de un modo más explícito a la luz de la inteligencia agente en el tratado De Anima; se trata aquí de una inteligencia que está siempre en acto y que permite la existencia en nuestro intelecto de una luz análoga, participada, otorgándole la capacidad de pasar del estado de potencia al estado del acto -intellectus in effectu o intellectus in adeptus ab alio. El Gundisalino recoge en este punto la doctrina de un intelecto agente universal, que ahora viene a ser interpretado como Dios mismo, pero sin obviar la propia luz de la humana facultad: encontramos en ello la original aportación de Domingo Gundisalvo a la historia de la filosofía medieval sobre el intelecto agente. Por otra parte, y como venimos sosteniendo en este artículo, su aportación en este caso se encuentra en plena consonancia con las proposiciones presentadas en su obra metafísica.

En efecto, en el De processione mundi Dominicus Gundissalinus había estudiado la estructura del ente creado y su procedencia de una causa primera; advirtiendo ahí que las facultades intelectuales humanas únicamente podían acceder al ser de la cosa en la medida en que la forma de estas se comporta como la luz que declara y permite ver al entendimiento lo que la cosa es. Se expresó entonces del siguiente modo: «Por ello la forma se llama oportunamente ornato y luz de la materia, (pues) así como la luz suele declarar la forma de la cosa y desvelar su ocultamiento, así por la forma aparece la materia, sin la cual se oculta en la potencia» ${ }^{21}$. La recurrencia a la noción de luz para expresar la forma de la cosa no es en este momento un mero recurso literario. Antes bien, de influencia gabiroliana ${ }^{22}$, resulta la expresión adecuada de una metafísica que acoge la teoría de la emanación para explicar la creación en un contexto de trascendencia ${ }^{23}$.

19 Ed. cit., p. 5, 24-26; cfr. Enders, J. A., «Die Nachwirkung von Gundissalinus 'De immortalitate animae'», en Philosophisches Jahrbuch, 12 (1889), pp. 382-392; Schneider, A., Die Psychologie Alberts des Grossen, nach der Quellen dargestellet, Münster, 1903, esp. pp. 403-447. En 1976 Allard, B. C., puso en cuestión la autenticidad de esta obra, en su artículo: «Note sur le De immortalitate animae», en Bulletin de philosophie médiévale, 18 (1976), pp. 68-72.

20 De Anima, pp. 98-99, 33 y $1-5$.

21 De processione mundi, n. 43.

22 Cfr. Brunner, F., Métaphysique d'Ibn Gabirol et de la tradition platonicienne, Ashgate, Aldershot, Hampshire (gran Bretaña)-Brookfield, Vermont (USA), 1997.

23 Cfr. Bultmann, R., «Zur geschichte der Lichtsymbolik im Altertum», en Philologus, 97 (1948), pp. 1-36; Semmelroth, O., «Gottes austrahlendes Licht zur Schofungs-und Offenbarungslehre des Ps. Dionysius Areopagita», en Scholastik, 28 (1953), pp. 481-503. 
Asimismo, en ese contexto de trascendencia, Dios es la máxima luz que irradia la forma que ilumina en las cosas: «Pues todas las formas procedentes de la formas procedentes de la forma simple y primera de la divinidad aquí, como en cierto espejo, se multiplican con diferentes rostros y son aquí en verdad como ciertas imágenes grabadas de aquella forma. Pues la creación de las cosas por el creador no es sino la salida de la forma de su sabiduría y voluntad; y su impresión en imagen en la materia es a semejanza de la salida del agua que emana de su origen y su curso» ${ }^{24}$.

Pues bien, continuando con el paralelismo establecido anteriormente, Domingo Gundisalvo, en su obra de psicología filosófica, va a establecer la necesidad de una facultad intelectual capaz de captar la forma de las cosas y de unirse a la primera luz del Intelecto Absoluto o inteligencia agente ${ }^{25}$. Este Intelecto Absoluto es caracterizado como luz que está siempre en acto y que infunde en el alma su luz para que ésta aprehenda la más pura forma simple mediante luce intelligentiae agentis, como expresa en el De anima ${ }^{26}$, mostrando con ello la vinculación final de la actividad intelectiva humana a la luz primera y fuente de la vida. Esta coherencia observada entre la obra metafísica y la obra gnoseológica de nuestro autor es precisamente una señal que nos hace presumir la autenticidad del De anima ${ }^{27}$.

Es para nuestro propósito importante el capítulo décimo de ese tratado. Señala ahí que el alma racional se caracteriza por tener dos facultades: $«$ Animae rationales duae sunt vires ${ }^{28}$ : una es la virtus intelligendi y la otra es la virtus agendi. Esta última es denominada intellectus activus, y se dirige hacia las acciones corporales, orientando la acción humana. Mientras que la primera es la facultad contemplativa, que tiene por objeto las cosas superiores. $\mathrm{El}$ entendimiento contemplativo es informado por las formas universales abstraídas de la materia.

Uno y otro entendimiento pueden hallarse en pura potencia (intellectus materialis), donde el término «material» se aplica a semejanza de la materia primera, que, de por sí, no tiene ninguna forma, pero es capaz de recibir todas las formas. Y se hallan en «potencia fácil» cuando han recibido sus principios propios: proposiciones probables en el caso de la facultad activa, y los primeros principios en el caso de la facultad contemplativa; se habla entonces de intellectus in habitu o intellectus in effectu ${ }^{29}$. Ahora bien, cuando el intelecto contemplativo, al nivel de la perfectio, se encuentra en efecto absoluto, es decir, cuando la forma entendida está presente en él, la entiende en su efecto y entiende que entiende, entonces se denomina - siguiendo el modo de expresión aviceniano- intellectus in adeptus ab alio, lo cual implica su dependencia de algo exterior ${ }^{30}$. El intellectus adeptus es denominado así porque el intelecto que está en potencia no puede pasar al acto si no es por un intelecto que se halle siempre en acto

\section{De processione mundi, n. 43.}

25 «Sic anima rationalis cum coniungitur formis aliquo modo coniunctionis ex luce intelligentiae agentis, aptatur ad hoc ut subsistant in ea ipsae formae nudae ab omni permixtione...», De Anima, p. 89, 2-4.

26 De Anima, p. 88, 33.

27 No obstante, Alonso Alonso, M., atribuye esta obra a Juan Hispano, con argumentos que aún hoy merecen ser estudiados: «Gundisalvus y el Tractatus De Anima», en Pensamiento, 4 (1948), pp. 71-77. Mientras que Gilson, E., lo considera de Gundisalvo: «Les sources gréco-arabes de l'augustinisme avicennisant», en Archives d'Histoire Doctrinale et Littéraire du Moyen Âge (1927), pp. 89-149. También Baeumker, Cl., «Dominicus Gundissalinus als philosophischer Schriftsteller», en Studien und Charakteristiken zur Geschichte der Philosophie insbesondere des Mittelalters, Münster, Aschendorffschen, 1927, pp. 255-275. Resulta fundamental el estudio de Löwenthal, A., Pseudo-Aristotele über die Seele. Eine psychologische Schrift des XII Jahrhunderts und ihre Beziehungen zu Salomo ibn Gabirol, Berlín, Mueller und Mueller, 1891. Y más reciente: Abelloos, E. B., «Un cinquème du 'Tractatus De Anima' de Dominique Gundissalinus», en Bulletin de Philosophie Médiévale, 14 (1972), pp. $72-85$.

28 De Anima, p. 84, 20

29 De Anima, p. 87.

30 «Cum enim intellectus contemplativus est in effectu absoluto, scilicet cum forma intellecta est sibi praesens et considerat eam in effectu et intelligit in effectu et intelligit se intelligere in effectu, quod tunc est in ea, vocatur intellectus in adeptus ab alio», De Anima, pp. 87-88, 38 y 1-3. 
(in effectu): «Qui ideo vocatur intellectus adeptus ab alio quoniam intellectus in potentia non exit ad effectum nisi per intellectum qui semper est in effectu» ${ }^{31}$. Así pues, nuestro intelecto - cuando es in adeptus ab alio - recibe de éste último las especies de las cosas, pudiéndose afirmar que posee propiamente la luz de aquella inteligencia agente, que está siempre en acto ${ }^{32}$.

La inteligencia siempre en acto es la luz que da la luz a nuestro intelecto, permaneciendo en el alma propiamente esa luz, y, por ende, las formas de las cosas: tal es a mi juicio el giro propuesto por Gundisalvo a las doctrinas precedentes. Es decir, sin llegar a elaborar sistemáticamente la doctrina de un intelecto agente propio en el ser humano, al modo como posteriormente lo hará Tomás de Aquino ${ }^{33}$, afirma sin lugar a dudas la presencia inmanente a las facultades humanas de la luz del intelecto agente. Ciertamente, es para ello necesario que nuestro intelecto se una - de algún modo - a aquella inteligencia que se halla ya en acto y que imprime en él las especies; pero no lo es menos que, finalmente, la especie se halla en el intelecto humano que ve con su propia luz ${ }^{34}$.

La inteligencia primera que da la forma inteligible es comparada con respecto a nuestra alma con el sol, por el cual son vistos los colores, y entonces, «así como sin la luz exterior no se produce la visión, sin la luz de la inteligencia agente en nosotros, no se da ninguna comprensión de la verdad de la cosa ${ }^{35}$. Esta comprensión implica una abstracción de los inteligibles (intelligibilia) a partir de las formas presentes en la imaginación (imaginabilia) ${ }^{36}$; abstracción que es, en la obra gundisalina - y en perfecto acuerdo con su doctrina metafísica de la processio de todas las cosas a partir del primer ser - una suerte de emanación de la formas a partir de la primera intelligentia agens. Pero -insistimos- este proceso emanativo no suprime en modo alguno la luz propia del intelecto humano, ni su operatividad, que consiste en disponerse para contemplar la formas inteligibles, lo cual constituye una auténtica acción del alma: «Item virtus intellectiva abstrahit intelligibilia a quantitate et loco et situ et ceteris omnibus» ${ }^{37}$. La abatracción es propia del intelecto humano, de tal modo que lo inteligido es propiamente en el intelecto la forma de la cosa, que recibe también el nombre de similitudo y permanece en la mente del que entiende ${ }^{38}$.

Como se ha escrito: «Cuando la forma de una cosa se comprende por el entendimiento, que es la acción (actus) del alma, aquella media concepción de la verdad de la cosa, que nace en la cosa entendida por el entendimiento agente (intellectus agens) y por el alma pasiva (anima patiens), se llama entendimiento pasivo. Este es intermedio entre el entendimiento por el cual entendemos, que es la acción (actus) del alma y el entendimiento, es decir, la cosa que entendemos, o sea, la analogía (similitudo), cuya forma retenemos, en la mente ${ }^{39}$. Gundisalvo en efecto afirma sin reservas que la forma intelecta habet esse in intellectu y que el alma en cuan-

\section{De Anima, p. 88, 3-5.}

32 Sobre la «corrección» de Gundisalvo a Boecio en lo que se refiere a la intelección de la ciencia divina: Fidora, A., «La metodología de las ciencias según Boecio: su recepción en las obras y traducciones de Domingo Gundisalvo», en Revista Española de Filosofia Medieval, 7 (2000), pp. 127-136, esp. pp. 132-135.

33 Cfr. Tomás de Aquino, Suma contra gentiles, lib. II, caps. 59-79.

34 «Unde cum intellectus qui est in potentia coniungitur cum illo intellectu qui est in actu aliquo modo coniunctionis, imprimitur in eo aliqua species formarum quae est adepta ab extrinsecus», De Anima, p. 88, 9-11.

35 De Anima, p. 88, 13-15.

36 «Imaginabilia enim sunt intelligibilia in potentia et fiunt intelligibilia in effectu, non ipsa eadem, sed quae extrahuntur ex illis», De Anima, p. 88, 36-38.

37 De Arima, p. 39, 6.

38 «Cum enim forma rei sicut est ab intellectu qui est actus animae comprehenditur, illa media veritatis rei conceptio quae $a b$ intellectu agente in rem intellectam et ab anima patiente ab ea generatur, dicitur intellectus passive medius inter intellectum quo intelligimus, qui est actus animae, et intellectum scilicet rem quam intelligimus, hoc est, cuius formae similitudinem in mente retinemus. Unde quia intellectus non est nisi similitudo formae rei quae in mente concipitur, a philosophis similitudo vocatun», De Anima, p. 89, $20-26$.

39 Kinoshita, N., o. c., p. 63. 
to sujeto de los inteligibles, no es cuerpo, sino espíritu; esto es, una sustancia compuesta con la forma de la espiritualidad y de la racionalidad ${ }^{40}$.

Finalmente, que el alma humana posee la capacidad propia, aunque análoga y participa$\mathrm{da}$, de la inteligencia agente, es precisamente lo que permite a nuestro autor defender la inmortalidad del alma humana en el De immortalitate animae; donde el principal argumento filosófico consiste en sostener que una sustancia inteligente debe incorruptible, pues sólo las formas materiales son corruptibles. Una sustancia así recibe o conoce las formas (species) de las formas materiales, precisamente por no ser material y no depender su actividad de órgano corporal alguno ${ }^{41}$. La actividad intelectiva o Vita uirtutis intellectiuae no es sino el mismo intellectus in effectu, que recibe su luz de lo más noble, esto es, de lo que se halla separado de la materia ${ }^{42}$.

En conclusión, puede sostenerse la tesis que en su momento E. Gilson presentó sobre Gundisalvo, a saber, que su gnoseología trata de coordinar un universo neoplatónico como el de Avicena, con la doctrina tradicional —de corte agustiniano- del Dios iluminador ${ }^{43}$. No obstante, la progresiva profundización en los textos y en la historia del intelecto en la edad media, permite avanzar que se halla en Gundisalvo un intento innovador en lo que se refiere a la fijación de la estructura de las facultades cognoscitivas humanas; y ello de tal modo que debe afirmarse sin reservas que prepara el desarrollo de la doctrina del intelecto agente en el siglo XIII; y, más en concreto, en la dirección de la afirmación de una luz propia e individual en cada una de las almas humanas cognoscentes, cuando se dispone para unirse a la inteligencia de la cual emana la forma entendida ${ }^{44}$.

$\mathrm{M}^{\mathrm{a}}$ Jesús Soto Bruna Universidad de Navarra Departamento de Filosofía Edificio de Bibliotecas

E-31080 Pamplona mjsoto@unav.es

40 Cfr. De Anima, p. 39, 10-13 y p. 42; Callus, D. A., «Gundissalinus 'De anima' and the problem of Substantial Form», en The New Scholasticism, (1939), pp. 338-355.

41 Cfr. De immortalitate animae, p. 5, 7-11 y p. 6, 5-20. Cfr. asimismo el estudio de G. Bülow, en la edición que utilizamos, sobre la autoría gundisalina de esta obra.

42 «Manifestum est uirtutem istam nobilem aut esse duarum facierum, quarum altera illuminabilis est desuper, a rebus scilicet nobilius, incorporalibus, scilicet spoliatis a materia et ab appendiciis ipsius, altera, illuminabilis a parte inferiori, uidilicet corporalium et sensibilium (...). Sed a superiori est nobilior eius perfectio et lumen nobilius», De immortalitate animae, p. 19, 6-15; adviértase el paralelismo con las dos facultades presentadas en el $D e$ Anima.

43 Cfr. Gilson, «Les sources gréco-arabes de l'augustinisme avicennisant», art. cit., p. 91.

44 «Dum autem anima humana generaliter est in corpore, non potest recipere intelligentiam agentem subito. Sed eius dispositio est sicut dicimus. (...) Hic autem modus intelligendi in potentia est virtus quae acquirit animae intelligere cum voluerit, quia cum voluerit coniungetur intelligentiae a qua emanat in eam forma intellecta», $D e$ Anima, p. 95, 1-11. 